\title{
0 Turismo Como Experiência e Como Desejo de Território e de Viagem
}

https://doi.org/10.21814/uminho.ed.48.4

\author{
Moisés de Lemos Martins
}

Centro de Estudos de Comunicação e Sociedade, Instituto de Ciências Sociais, Universidade do Minho, Braga, Portugal https://orcid.org/0000-0003-3072-2904

moisesm@ics.uminho.pt

\section{Resumo}

O ponto de vista que vou desenvolver sobre o turismo não se prende com uma análise económica, nem sequer com uma análise política stricto sensu. Vou configurar o turismo como uma atividade cultural. Por esta razão, o ponto de vista que vou desenvolver sobre o turismo é fenomenológico e sócio-antropológico. Não vou refletir, pois, sobre o negócio (nec/otium - não/lazer; atividade, trabalho, comércio), mas sobretudo sobre ócio (otium - tempo livre de atividade).

\section{Palavras-chave}

cultura de massas, experiência da viagem, experiência eletrónica, território, turismo cultural

\section{Um Desejo de Território}

Gostaria de começar por assinalar que o turismo reflete a nossa atual obsessão por um território e pela viagem num território ${ }^{1}$. Digo obsessão, porque se trata de um movimento que corresponde a estratégias de regresso ao território, a um território

1 As figuras de territorialização, desterritorialização e reterritorialização foram desenvolvidas, sobretudo, por Deleuze e Guattari, primeiro em Anti-Oedipe (1972), e depois em Mille Plateaux (1980) e em Qu'Est-Ce Que la Philosophie? (1991). A ideia que eu proponho aqui é a de que a atual mobilização tecnológica do humano, total (Jünger, 1930/1990) e infinitamente (Sloterdijk, 2000), para uma qualquer competição, um qualquer mercado e uma qualquer estatística, teve como consequência um movimento de desterritorialização suprema (Martins, 2007, 2010b, 2019), com a consequente perda dos três acentos do tempo, os quais Paul Celan (1971/1996) entendia como definidores da condição humana: o agudo da atualidade, o grave da historicidade e o circunflexo, que é um sinal de expansão do tempo, da eternidade. 
físico e espiritual, na procura de possibilidades de encontro com o outro, quando os atuais territórios nos oferecem, cada vez mais, paisagens, atmosferas e ambientes eletrónicos, sendo a nossa vida uma circum-navegação de territórios digitais e virtuais (Maffesoli \& Martins, 2011; Martins, 2012, 2017b).

Começo, pois, por figurar o turismo como uma estratégia humana de regresso ao território e à viagem num território (físico ou espiritual), na procura de uma resposta à aceleração da nossa época e à sua mobilização eletrónica. Uma tal resposta é feita de estratégias híbridas, por vezes ambíguas, e sempre complexas, como híbrido, ambíguo e complexo é o humano, na travessia tecnológica, que está convocado a fazer. Com efeito, não é possível esquivarmo-nos, hoje, ao debate sobre a técnica e ao papel que as novas tecnologias, que incluem os média, "têm na redefinição da cultura, ou seja, na delimitação do humano” (Martins, 2010a, p. 84). Porque este é o nosso tempo e não temos outra época para viver senão esta, a da mobilização tecnológica do humano, precisamos de estar à altura destas circunstâncias (Martins 2010b, 2011/2017a, 2012).

Quando, hoje, perguntamos a alguém onde mora, o mais habitual é a resposta ser-nos agora dada em tempo: a 10/15 minutos de carro do emprego; ou então, a meia hora de autocarro da universidade. Medido em tempo, um lugar como que já não é sobretudo um território, um espaço, um sítio que se habita. Penso, no entanto, que o atual frenesim do turismo nos revela uma consciência um tanto infeliz, ou seja, um certo mal-estar (Martins, 2015). É que o território é hoje um lugar por onde se viaja de GPS, com o espaço a ser medido por coordenadas. Cada vez mais a experiência que temos do território é eletrónica. Os filmes publicitários de territórios são eletrónicos; os territórios, mostrados nos portais da internet, dão-nos a ver paisagens virtuais, bem distantes das paisagens reais; as viagens e os destinos para viagens procuramo-las em portais eletrónicos de agências turísticas; os bilhetes para destinos turísticos compramo-los através da internet.

Sem dúvida que a experiência eletrónica expande a nossa capacidade de efabular, de contar histórias, de fazer narrativas, usando recursos de vários média, que compreendem vários formatos técnicos e várias linguagens: fotografias; postais ilustrados; selfies; vídeos; filmes e outros média (Martins, 2020b).

Existe, no entanto, qualquer coisa de melancólico, nesta viagem, que é em larga medida digital e virtual, com paisagens, atmosferas e ambientes eletrónicos (Martins, 2017b). Viajar através de sites web, portais, redes sociotécnicas, repositórios digitais e museus virtuais é uma experiência um tanto melancólica, porque mais do que fruir as coisas mesmas, fruímos as imagens delas, em selfies no Facebook, ou no Instagram, consumimos imagens que se consumam aí.

A esta experiência eletrónica, a um tempo digital e virtual, alguns dão-lhe o nome de "abandono do território", de "desterritorialização". Porque na aceleração e na mobilização tecnológicas, deixámos de ter fundamento sólido e seguro, território conhecido e controlado, e identidade estável e garantida. 


\section{A Experiência da Viagem}

O segundo aspeto que vou desenvolver neste ensaio é a experiência da viagem, que é sempre uma possibilidade de encontro - de encontro com o outro e de encontro com a natureza ${ }^{2}$. Mas a viagem eletrónica, ao encontro do outro e da natureza, não tem o corpo do outro, nem a rugosidade da natureza. Tem, sim, sobretudo, ficções do outro, simulacros, efervescências e euforias do outro, e mesmo o espetáculo do outro - os quais, nas palavras de Guy Debord (1967/1991), não passam de "guardiões do sono da razão" (p. 16; entenda-se, da razão do outro: da sua diferença, diversidade e autenticidade $)^{3}$.

Eu diria que o turismo é uma arte das ligações, sabendo nós, pelo Banquete de Platão (1986), que uma arte das ligações é uma erótica. Portanto, não é falso dizer que o turismo é uma erótica, que tem sex-appeal, como diz Mario Perniola (1994/2004) dos objetos técnicos. Os territórios, tal como os seus povos e culturas, são experienciados, enfim, vividos, pelo turista. E como experiência, o turismo envolve, hoje, todos os aspetos da vida quotidiana do próprio turista, no local para onde se desloca: compras, refeições, bebidas, entretenimento, diurno e noturno. $E$ tanto como experienciar os monumentos do mundo, o próprio turista torna-se parte do produto turístico que vivencia.

A cultura, no seu sentido amplo, que é o sentido antropológico, é fonte sempre crescente de experiências e possibilidades. Por essa razão, podemos dizer que todo o turismo é cultural. 0 turismo, hoje, é um "fenómeno social total", nos exatos termos com que o antropólogo Marcel Mauss (1966) caraterizou os fenómenos que totalizam a existência.

De facto, hoje, o turismo envolve a vida inteira de um turista. Podemos imaginá-lo a ir de manhã à praia, à tarde a um museu e à noite a dar uma volta pela parte antiga de uma cidade. E é bem provável que o primeiro encontro de um turista com a cultura seja com o menu de um restaurante, e com o empregado e a comida desse restaurante, perto de uma estância turística. A motivação do turista é aprender, descobrir, experimentar e consumir as atrações culturais, tangíveis e intangíveis, num destino turístico (Piñeiro-Naval \& Sierra, 2018, pp. 10-16).

\footnotetext{
2 Todos nós andamos a ensaiar o humano, o que quer dizer, a ensaiar uma ideia de viagem. Mas, necessariamente, de uma viagem atribulada, cheia de perigos e obstáculos a transpor. Andamos a ensaiar a viagem como errância, enigma e labirinto, e também como rugosidade, viscosidade e incerteza. Todos andamos a ensaiar a viagem como dúvida, embora, da mesma maneira, como memória de caminhos já andados e de experiências já vividas. Retomo de João Guimarães Rosa, em Grande Sertão - Veredas, a figura de "travessia", que aponta para uma viagem particularmente rugosa, incerta, enfim, para uma viagem difícil (Guimarães Rosa, 2011).

3 A ideia de "crise da experiência" começa por ter um equivalente em Benjamin (1992) na figura de "crise do narrador", e parece hoje em fase imparável pela aceleração tecnológica do nosso tempo. Agamben (1978/2000) fala da impossibilidade em que nos encontramos, hoje, de nos apropriarmos da nossa condição propriamente histórica, o que torna "insuportável o nosso quotidiano" (p. 20). Perniola (1991/1993,1994/2004), por sua vez, ao caraterizar a experiência contemporânea, introduz o conceito do "já sentido" e interroga-se sobre o sex appeal do inorgânico, que tem tanto de fascinante como de inquietante. Quanto a Baudrillard (1981), conhecemos o seu conceito de realização do real como simulacro.
} 
E essas atrações, ou seja, esses produtos, referem-se a um conjunto de caraterísticas materiais, intelectuais, espirituais e emocionais, distintivas de uma sociedade, que compreende artes e arquitetura, património histórico e cultural, património culinário, literatura, música, indústrias criativas e culturas vivas, e que compreende, ainda, os seus sistemas de valores, crenças e tradições (Pinto-Coelho \& Pinto, 2018). Aqui temos, pois, o turismo como um fenómeno social total, porque envolve a vida de um indivíduo e a condiciona em todos os seus aspetos.

\section{O Turismo, as Massas e as Máquinas}

O turismo é um fruto da civilização das "massas e das máquinas", nos exatos termos em que Ernst Jünger (1930/1990, p. 108) caracterizou os séculos XIX e XX. Mas sendo o turismo um acontecimento da modernidade, é justo ter presente a observação do sociólogo moçambicano, Elísio Macamo (2005), sobre o facto de Moçambique ter entrado ambiguamente na modernidade, uma vez que o fez através da colonização.

Como fenómeno de massas, o turismo nasceu por meados do século XIX, com a sociedade industrial e a distinção entre tempo de trabalho e tempo de lazer, e desenvolveu-se sobretudo depois da Segunda Guerra Mundial, com a afirmação do estado de bem-estar social - o welfare state.

Afirmou-se, então, num primeiro momento, à volta de três Ss: sand, sun e sea (areia, sol e mar). Mas podemos dizer que o turismo é a experiência que as massas têm da viagem - uma mobilização por máquinas, desde a escolha de destinos na internet, até à reserva de alojamento e à reserva do voo numa ligação eletrónica, com uma agência de viagens, para destinos remotos, exóticos e arcaicos, cada vez mais experienciados como acontecimentos únicos: singulares, diferentes e autênticos. Enfim, tais experiências, que Pine e Gilmore (1998, p. 97) designam como "memoráveis", vão ser imediatamente ecoadas e perpetuadas como "instantes eternos", através de fotografias, selfies, imagens panorâmicas e vídeos. Bem significativo e muito adequado é, no entanto, o facto de o livro de Michel Maffesoli, L'Instant Éternel, publicado em 2000, ter como sub-título "o regresso do trágico nas sociedades pós-modernas", porque a experiência turística é, sem dúvida, uma experiência um tanto melancólica. Mas este aspeto apenas o desenvolvo no ponto seguinte.

\section{A Porta e a Ponte}

Neste ponto, vou analisar o turismo, retomando duas formas sociais exemplares, que Georg Simmel (1988, pp. 161-168) identifica como fautoras de socialidade: a "porta" e a "ponte". A "porta" permite a saída para o encontro do outro. É preciso sair de si próprio e do seu lar para encontrar o outro. A polis, ou seja, a cidade dos homens, nasce deste encontro. $O$ bem coletivo, o que quer dizer, a ideia de comunidade como totalidade, que integra as margens (minorias, migrantes, exilados, refugiados, debilitados, incapazes) nasce deste movimento que a "porta" simboliza, como movimento altruísta, cooperativo e solidário (Martins, 2019). 
A ponte é, pois, um recurso de socialidade, uma mediação, lá onde o caminho fica bloqueado e sem saída. É um recurso que estabelece a circulação entre pessoas e que permite manter a utopia de uma comunidade. E o turismo assume hoje esta condição: permite a circulação fora de portas, como ponte, permite desbloquear caminhos tapados e horizontes fechados. Na cultura global, aberta pelas tecnologias da informação e da comunicação, predominam, de facto, os fluxos, incluindo os fluxos de pessoas, "turistas, imigrantes, refugiados, exilados, trabalhadores convidados e outros grupos e indivíduos em movimento" (Piñeiro-Naval \& Serra, 2018, p. 10).

No entanto, o modo como o turismo se faz "porta" " "ponte", e também "etnopaisagem" (Appadurai, 1996, p. 33), enferma, a meu ver, de um mal. Não o vejo a abrir para um sentido de comunidade, porque não tem a polis como horizonte, não projeta uma utopia, nem constitui uma promessa coletiva. $O$ turismo não existe em função da comunidade. 0 turismo realiza-se (consuma-se) no consumo. E daí a sua tragédia: é um “instante eterno", na expressão de Maffesoli (2000), mas não é a configuração da eternidade do humano, o que apenas a promessa de um horizonte de comunidade lhe poderia facultar. É isso, aliás, o que nos é lembrado pelo poeta argentino, Jorge Luís Borges (1966/1988), em "The Unending Gift": "na promessa algo há de imortal; nela alguma coisa vive para sempre". A polis tem, pois, uma exigência de cidadania e o turismo, de um modo geral, contraria esta exigência.

O turismo, muitas vezes, é multidão, são massas, aceleradas e mobilizadas para o consumo, por máquinas poderosas de transporte (por terra, mar e ar: aviões, cruzeiros, comboios, viaturas automóveis...), além de poderosas indústrias, de hotelaria, de viagens e de férias.

Vou, todavia, de seguida, apontar para uma possibilidade de comunidade no turismo. Será esse o objeto do próximo e último ponto, em que articulo a atividade turística com o património.

\section{O Turismo e o Património}

O meu propósito, neste último ponto, é interrogar a estratégia turística de regresso ao território, através do património, que é uma estratégia em que a indústria turística investe cada vez mais. A relação do território com o património é evidente, pelo menos em três dimensões: o património é por natureza de ordem espacial; a geografia económica e cultural contemporânea dá-lhe atenção; a sociedade toma-o como um bem económico e cultural.

Caraterizemos, agora, o património. O património compreende um entrançado de bens materiais e imateriais, um entrançado de bens, que inclui um domínio material e tangível, de paisagens naturais e de conjuntos edificados, sítios e monumentos, e que também compreende uma dimensão imaterial, de tradições orais e práticas sociais (Ashworth et al., 2007).

A utilização do passado, ou seja, as práticas de patrimonialização, decorre de um processo social seletivo de construção (ou de ativação) e regulação, de acordo com uma 
escala de valores e significados, com consequências materiais (Carvalho \& Fernandes, 2012). 0 atual processo de aceleração e mobilização tecnológica do humano para o digital e o virtual, com a consequente perda do fundamento seguro, do território conhecido e da identidade estável, a que já aludi, tem como efeito uma feroz reação para preservar memórias e criar identidades. É a esse movimento que chamo de uma nova estratégia de regresso ao território, uma nova estratégia com novas práticas de territorialização. Numa estratégia feroz e desesperada, que dá vazão a este desejo obsessivo de regresso ao território, o património compreende jardins, literatura, indústria, caminhos de ferro, arquitetura militar e industrial, gastronomia, e chega a compreender espaços de reclusão, sofrimento, tragédia ou privação.

\section{Nota Conclusiva}

Tal como já assinalei atrás, os territórios são portas e pontes para o encontro com o outro, são possibilidades de encontro. E são mesmo pontos de encontro. E, ao serem pontos de encontro, constituem-se como possibilidades de construção da polis, como possibilidades de construção da comunidade. Ora, no património também está o outro, seja o património espaço físico (bem tangível, material), seja o património espaço mental (bem intangível, imaterial). Daí que possamos falar de encontros com o património, que são, todavia, cada vez mais, encontros mediados por recursos digitais. E os cidadãos, tanto usam média digitais para comprar e vender património, em leilões da internet, como usam média digitais para aprender a história dos lugares dos objetos. É um facto, para muita gente, e sobretudo para os mais jovens, o digital é hoje, a ponte, e mesmo a porta de entrada nas experiências com o património.

\section{Agradecimentos}

Este trabalho é financiado por fundos nacionais através da FCT - Fundação para a Ciência e a Tecnologia, I.P., no âmbito do projeto UIDB/00736/2020. É também apoiado no âmbito da "Knowledge for Development Initiative", pela Rede Aga Khan para o Desenvolvimento e pela FCT - Fundação para a Ciência e Tecnologia, IP (n. ${ }^{\circ}$ 333162622) no contexto do projeto Memories, cultures and identities: How the past weights on the present-day intercultural relations in Mozambique and Portugal?

\section{Referências}

Agamben, G. (2000). Enfance et histoire. Payot \& Rivages. (Trabalho original publicado em 1978)

Appadurai, A. (1996). Modernity at large: Cultural dimensions of globalization. University of Minnesota Press.

Ashworth, G., Graham, B., \& Tunbridge, J. (2007). Pluralising pasts: Heritage, identity and space in multicultural societies. Pluto Press.

Baudrillard, J. (1981). Simulacres et simulation. Galilée.

Benjamin, W. (1992). Sobre arte, técnica, linguagem e política. Relógio d'Água. 
Borges, J. L. (1988). Elogio da sombra. Obras Completas (1952-1972)(Vol. II). Teorema. (Trabalho original publicado em 1966)

Carvalho, P., \& Fernandes, J. L. (Eds.). (2012). Património cultural e paisagístico. Políticas, intervenções e representações. Imprensa da Universidade de Coimbra.

Celan, P. (1996). Arte poética. 0 meridiano e outros textos. Colibri. (Trabalho original publicado em 1971)

Debord, G. (1991). A sociedade do espectáculo (F. Alves \& A. Monteiro, Trad.). Mobilis in Mobile. (Trabalho original publicado em 1967)

Deleuze, G., \& Guattari, F. (1972). L'anti-Oedipe. Éditions de Minuit.

Deleuze, G., \& Guattari, F. (1980). Mille plateaux. Éditions de Minuit.

Deleuze, G., \& Guattari, F. (1991). Ou'est-ce que la philosophie? Éditions de Minuit.

Guimarães Rosa, J. (2011). Grande sertão - veredas. Editora Nova Fronteira.

Jünger, E. (1990). L'etat universel - Suivi de la mobilisation totale. Gallimard. (Trabalho original publicado em 1930)

Macamo, E. (Ed.). (2005). Negotiating modernity: Africa's ambivalent experience. Zed Books.

Maffesoli, M. (2000). L'instant éternel. Le retour du tragique dans les sociétés postmodernes. Denoël.

Maffesoli, M., \& Martins, M. L. (2011). À propos de l'imaginaire des médias. Sociétés, (111), 5-9. http://hdl. handle.net/1822/23797

Martins, M. L. (2007). Nota introdutória. A época e as suas ideias. Comunicação e Sociedade, 12, 5-7. https://doi.org/10.17231/comsoc.12(2007).1092

Martins, M. L. (2010a). Linguagem, verdade e conhecimento. As ciências da comunicação e o contemporâneo. In A. S. da Silva, J. C. Martins, L. Magalhães, \& M. Gonçalves (Eds.), Comunicação, cognição e média (Vol. 1; pp. 76-86). Faculdade de Filosofia Universidade Católica Portuguesa. http://hdl.handle. net/1822/24118

Martins, M. L. (2010b). A mobilização infinita numa sociedade de meios sem fins. In C. Álvares \& M. Damásio (Eds.), Teorias e práticas dos media. Situando o local no global (pp. 267-279). Edições Universitárias Lusófonas. http://hdl.handle.net/1822/24250

Martins, M. L. (2012). Média digitais: Hibridez, interactividade, multimodalidade. Revista de Comunicação e Linguagens, 43/44, 49-60. https://doi.org/10.3917/soc.111.0017

Martins, M. L. (2015). Os estudos culturais como novas humanidades. Revista Lusófona de Estudos Culturais, 3(1), 341-361. http://hdl.handle.net/1822/40655

Martins, M. L. (2017a). Crise no castelo da cultura. Das estrelas para os ecrãs. Grácio Editor. (Trabalho original publicado em 2011)

Martins, M. L. (2017b). Prefácio: A circum-navegação de atmosferas e paisagens tecnológicas. In H. Pires, M. Curado, F. Ribeiro, \& P. Andrade (Eds.), Cibercultura: Circum-navegações em redes transculturais de conhecimento, arquivos e pensamento (pp. 11-18). Húmus. http://hdl.handle.net/1822/49352

Martins, M. L. (2019). A comunicação e a informação na cultura. Maremagnum, (23), 33-40. http://hdl. handle.net/1822/61843

Martins, M. L. (2020a). Em defesa da universidade e em defesa da ciência. In M. Oliveira, H. Machado, J. Sarmento, \& M. C. Ribeiro (Eds.), Sociedade e crise(s) (pp. 149-157). UMinho Editora. https://doi. org/10.21814/uminho.ed.21

Martins, M. L. (2020b). Tecnologia e literatura: As narrativas transmediáticas. Letras de Hoje, 55(1), e34786. https://doi.org/10.15448/1984-7726.2020.1.34786 
Mauss, M. (1966). The gift; forms and functions of exchange in archaic societies. Cohen \& West.

Perniola, M. (1993). Do sentir(A. Guerreiro, Trad.). Presença. (Trabalho original publicado em 1991)

Perniola, M. (2004). 0 sex appeal do inorgânico (C. David, Trad.). Ariadne. (Trabalho original publicado em 1994)

Pine, B. J., \& Gilmore, J. H. (1998). Welcome to the experience economy. Harvard Business Review, 76(4), 97-105.

Piñeiro-Naval, V., \& Serra, P. (2018). Cultura, património e turismo na sociedade digital: Uma perspetiva ibérica (Vol. I). UBI - Labcom.

Pinto-Coelho, Z., \& Pinto, R. (2018). Discursos e imagens do turismo cultural. Revista Lusófona de Estudos Culturais, 5(2), 7-21. https://doi.org/10.21814/rlec.335

Platão. (1986). O banquete. Europa-América.

Simmel, G. (1988). La tragédie de la culture et autres essais. Rivages.

Sloterdijk, P. (2000). La mobilisation infinie. Christian Bourgois. 